University of Nebraska - Lincoln

DigitalCommons@University of Nebraska - Lincoln

Educational Psychology Papers and

Publications

Educational Psychology, Department of

November 2003

\title{
Parent Involvement and Reading: Using Curriculum-Based Measurement to Assess the Effects of Paired Reading
}

Cathy L. Fiala

University of Nebraska-Lincoln

Susan M. Sheridan

University of Nebraska-Lincoln, ssheridan2@unl.edu

Follow this and additional works at: https://digitalcommons.unl.edu/edpsychpapers

Part of the Educational Psychology Commons

Fiala, Cathy L. and Sheridan, Susan M., "Parent Involvement and Reading: Using Curriculum-Based Measurement to Assess the Effects of Paired Reading" (2003). Educational Psychology Papers and Publications. 6.

https://digitalcommons.unl.edu/edpsychpapers/6

This Article is brought to you for free and open access by the Educational Psychology, Department of at DigitalCommons@University of Nebraska - Lincoln. It has been accepted for inclusion in Educational Psychology Papers and Publications by an authorized administrator of DigitalCommons@University of Nebraska - Lincoln. 


\title{
Parent Involvement and Reading: Using Curriculum-Based Measurement to Assess the Effects of Paired Reading
}

\author{
Cathy L. Fiala and Susan M. Sheridan \\ University of Nebraska-Lincoln
}

\begin{abstract}
This study examined the effectiveness of a paired reading intervention using curriculum-based measurement (CBM) probes to document reading progress for one fourth-and two third-grade students. These students were considered below-average readers. Parents and children used the paired reading method in their homes for 10 minutes, four times a week. Children and parents were also provided with reading material at their instructional level. Results showed that the children's reading accuracy and rates increased from baseline to follow-up on CBM measures and on pre/posttesting. In addition, students and parents gave favorable treatment acceptability ratings for paired reading. Implications for future research are outlined.
\end{abstract}

Illiteracy has staggering effects on society. Illiterate adults make up $75 \%$ of the unemployed, $33 \%$ of mothers receiving Aid to Families with Dependent Children, and $60 \%$ prison inmates (Adams, 1990). In addition, $85 \%$ of juveniles who appear in court are illiterate. Historically, reading has been associated with success in life. Reading may be even more important in today's information and technology age (Miller \& Kratochwill, 1996).

Longitudinal studies have shown that students exhibiting poor reading skills early in school are likely to have poor reading skills later (Good, Simmons, \& Smith, 1998). By identifying these children early in their school careers, intervention efforts may be more successful. The Matthew effect (Stanovich, 1986), in which the "rich get richer and the poor get poorer" occurs when poor readers encounter stress and fear of failure to a greater extent than good readers do. Poor readers do not enjoy reading, do not engage in reading, and spend less time-on-task, which perpetuates the continuation of poorer reading skills (Topping \& Lindsay, 1992). Conversely, students who enjoy reading spend more time-on-task and improve their reading skills. Intervention programs that provide the opportunity for extra reading practice and increased time-on-task can possibly alter the trajectory for reading achievement in poor readers, and lessen the effects of other concomitants of reading failure (e.g., dislike of school, poor academic self-concept) (Wagner et al., 1997).

\section{Importance of Parental Involvement in Children's Literacy}

Parent tutoring is an effective means for increasing students' academic performance (Graue, Weinstein, \& Walberg, 1983). Children's literacy experiences can be positively affected when parents are educated in how to help their children. Fredericks and Rasinski (1990) outline four criteria for successful parental reading involvement programs. They suggest that effective programs (a) involve real reading (i.e., reading out of books); (b) have enjoyable, efficient, and easy to implement activities; (c) provide a connection between home and school; and (d) provide consistency and commitment over the long term rather than a series of short-term or single activities. When these four criteria were met, children reported reading more often at home in their free time and with adults (Morrow \& Young, 1997).

Differences in literacy interactions between parents of good readers and parents of poor readers have been noted in the literature. Elliott and Hewison (1994) found that the parents of good readers tended to favor the orientation of reading for meaning, whereas parents of poor readers were

Correspondence: Cathy L. Fiala, 111 N. 6th Street, Howells, NE 68641. E-mail: Cfiala8@esu8.org 
found to emphasize the exercise of reading words rather than focus on content and meaning. Weinberger (1996) found that only 12 of 42 parents in her study felt they knew how reading was taught in school. According to McMackin (1993), "Once formal reading instruction begins . . . many parents feel inhibited about participating in their child's literacy development" (p. 142).

In summary, it is apparent that the home environment affects children's literacy. However, many parents do not know how reading instruction is delivered in schools, or how to help their child effectively. Schools are in a position to advise parents of effective reading strategies. By working within the home environment, many children's literary experiences can be enhanced. Thus, parent education is crucial.

\section{Integrity of Parent Tutoring Practices}

In a seminal study, Tizard, Schofield, and Hewison (1982) reported positive gains in reading for children whose parents simply listened to them read. Since that time, the practice of parents hearing their children read has been popularized (Toomey, 1993). In the Tizard et al. study, parents were invited to hear their child read two to four times a week, with no exact method being specified. However, without information about the method used, it is difficult to discern the conditions under which these children made progress. Other parent listening studies have followed but have not produced similar results (Toomey, 1993).

One way to educate parents is through training them in reading procedures. The literature supports three dominant types of parent training schemes: behavior training; pause, prompt, praise approach (PPP); and paired reading (PR). The behavior training approach teaches parents to reinforce the child for successful behavior by giving him/her tokens or approval. In the PPP method, parents are trained to administer praise, to pause to allow the child to self-correct, and to give prompts to help the child self-correct. The PR method teaches parents to read simultaneously with their child, and to support the child when he/she is reading independently (Toomey, 1993).

Leach and Siddall (1990) compared the effects of several different programs that involved parents and their beginning readers. Their study compared PPP, PR, hearing reading (parents listen to their children read), and Direct Instruction (parents are provided with scripted lessons and books to use with children). The results showed that Direct Instruction and PR produced the most significant results, with beginning readers taught by these methods achieving rates of progress two to three times greater than those in the hearing reading group. Support for PPP was not strong, although this group also outperformed the hearing reading group. These authors concluded that greater progress can be expected when parents are taught more precise instructional methods.

Although other techniques (e.g., Direct Instruction, PPP) involve relatively time-consuming training procedures, PR is a cost-effective method of increasing reading achievement (Toomey, 1993). PR also helps to control the amount of failure that below-average readers may experience, which makes reading a more enjoyable experience (Topping \& Lindsay, 1992). Law and Kratochwill (1993) provide the following description of PR:

The procedure consists of two phases: simultaneous and independent reading. The child is allowed
to choose any book and the child and parent begin reading out loud together in close synchrony (si-
multaneous reading). When the child makes a mistake, the parent supplies the correct word, the
child repeats it, and they continue reading. When the child feels confident enough to read alone, s/
he gives the parent a signal and the parent stops reading (independent reading). If the child makes a
mistake, the parent provides the correct word, the child repeats it, and the pair begin reading again
(p. 120).

Although the research in general provides support for PR, there have been several limitations. First, although many studies report training parents in PR, few report the integrity with which PR is 
carried out in the home [Law \& Kratochwill (1993) and Miller \& Kratochwill (1996) were exceptions]. Second, Law and Kratochwill (1993) reported that outcome studies have often measured effects using pre-and poststandardized measures. Such procedures may not provide a sensitive measure of true gains in reading ability because "an increase of only 1-2 more correct answers during the post-testing may be recorded as $2-3$ months of reading progress" (p. 140). A third limitation in previous PR research is that choice of reading material has been left to the child. Allowing the child free choice of reading material may lead to frustration if difficult material is chosen.

\section{Purpose and Research Questions}

The purpose of this study was to address the concerns with previous research in the area of reading. Specifically, the current study investigated the following questions: (1) Does parent tutoring via the PR method with controlled reading material produce increased accuracy and fluency based on curriculum-based measurement probes from grade level materials?; (2) Can parents implement the PR method with integrity following minimal training?; and (3) How do parents and children rate the acceptability of the PR intervention, and how closely do participants compare to matched peers following intervention?

\section{Method}

\section{Participants and Setting}

Participants in the study were three Caucasian students (two males and one female) all of whom lived in dual parent households. All parents were in their mid-thirties to forties, and all worked outside of the home. One student (Bob) was 9 years of age and in the fourth grade. The other students (Sue and Joe) were 8 years of age and in the third grade.

The students attended a public elementary school in a small, rural school district. The school had an enrollment of 83 (K-6) and operated on a typical 9-month school schedule. Due to small class sizes, the third and fourth grade classes were combined in one classroom, and all three students in the study had the same teacher. The third and fourth grades each had 12 students, for a total of 24 in the class. The three participants in this study were being instructed in the Silver Burdett reading series. According to the teacher, the reading instruction was characterized by a combination of phonics and whole language. None of the children were receiving special education services; however, one student (Bob) was receiving Title I reading services.

The primary investigator in this study was completing her internship in a school psychology program, and was the psychologist for the district. The research project was supervised by a university faculty professor.

\section{Materials and Assessment Procedures}

Screening Measures. Twelve students were referred to the investigator by their teacher. Upon referral, the teacher completed the Problem Behavior section of the SSRS Teacher form, Elementary level. Those students whose Problem Behaviors were rated in the Average range (based on standard scores) were invited for a screening interview with the first author. Parents signed a consent form for their children to participate in screening. During the screening interview, a set of reading probes at each students' grade level was administered. The probes used were the screening probes taken from Standard reading passages (Children's Educational Services, 1987). Three probes were administered and the median score (words correct per minute) was determined. Those reading at a rate of less than 70 words correct per minute were considered for the study. Five of the 12 students screened met this 
criteria. One of these students was excluded from the remaining screening procedures because he was receiving special education services.

A short form of the Wechsler Intelligence Scale for Children-III (WISC-III) (Wechsler, 1991) was administered to the four students whose reading rate was less than 70 words correct per minute. The short form consisted of the following subtests: Information, Similarities, Arithmetic, Vocabulary, and Block Design. Each of these subtests have high reliability (.95) and validity (.90) coefficients (Sattler, 1992). Children obtaining a score of at least 85 on the WISC-III Short Form, were considered for the study. All four students met this criteria.

Integrity Measures. Parents audiotaped all of the PR sessions. The first author scored each of the PR sessions until scores on the treatment integrity checklist reached $85 \%$ for 6 consecutive days, then checks were completed randomly. Using a treatment integrity checklist developed from Table 1, the first author scored $25 \%$ of the remaining sessions for each parent-child dyad. Information gained from these checks was used to determine review steps not being implemented by parents. The investigator then called parents to provide feedback on steps that were being implemented incorrectly.

Social Validity. Two forms of social validity were assessed in this study: social comparison and treatment acceptability. Curriculum-based measurement (CBM) probes were collected in the school setting on two comparison peers (one from each target child's grade) four times throughout the study to compare each target child's performance to that of peers. Peers were selected by the teacher, who was instructed to choose a student whose reading performance was considered "average." Probes for comparison peers were collected once during baseline and follow-up and twice during the PR phase. These probes were the same as those given to the participants.

Treatment acceptability questionnaires were completed by the students and parents following the completion of the study. The measure for the students was adapted from the Children's Interven-

Table 1

Paired Reading Session Outline

1. Warm-up time (a few minutes of informal conversation before beginning paired reading if needed).

2. Parent sets timer for 10 minutes.

3. Child chooses a story to read from the material provided to them.

4. Parent and child read simultaneously.

5. Parent intervenes when the child makes one of the following errors: substitutes one word for another, omits a word in the printed material, stops for longer than a parent count to three on one word.

6. Parent uses corrective procedure:

a. parent stops child;

b. parent points to the word and says it;

c. child repeats the word;

d. simultaneous reading resumes.

7. Child gives signal to read alone.

8. Parent quietly praises child for using signal.

9. Child begins reading alone.

10. Parent intervenes when the child makes an error as described above.

11. Parent uses corrective procedure as described above.

12. Parent praises child at least one time other than when the child gives the signal to read alone (i.e., reading a difficult word, sounding a word out, attempting a difficult word, etc.).

13. Cool down (informal time to talk about the story or session). 
tion Rating Profile (Witt \& Elliott, 1985), which is a Likert-type scale that assesses the child's acceptability of the intervention procedure. The parents completed an adapted version of the Intervention Rating Profile-15 (Witt \& Martens, 1983). The IRP-15 is a reliable (Cronbach alpha = .98; Martens, Witt, Elliott, \& Darveaux, 1985), 15-item, Likert-type scale that assesses the acceptability of intervention procedures. Six questions related to behavior problems were eliminated, and minor wording changes were made to ensure that questions were pertinent to the current study.

\section{Experimental Procedure}

Selection of Participants. The children were selected based on the following criteria:

1. Students displayed difficulty in the subject of reading as measured by CBM probes. If a student in grade 3 or 4 was reading below 70 words correct per minute, he/she was considered to be reading below instructional level for grade level material (Shapiro, 1996).

2. Students achieved a Full-Scale IQ score of 85 or higher as measured by a short form of the Wechsler Intelligence Scale for Children-III (WISC-III; Wechsler, 1991) administered by the first author.

3. Teacher rating on the Problem Behaviors section of the Social Skills Rating System (SSRS) (Gresham \& Elliott, 1990) was within the average range (standard score $=85-115$ ).

4. The parent reported that he/she would be available to perform tutoring and signed a consent form to perform the tutoring procedure, with the opportunity to withdraw from the study at any time.

Of the 24 students in the class, four met the outlined criteria for inclusion in the study. Written informed consent was obtained from the parents of these four students. All four parent-child dyads were trained in PR. Following training, one of the parent-child dyads failed to complete the required number of PR sessions within the first week of implementation (two instead of four). The sessions conducted were with high integrity. When the parent was contacted about this, the parent indicated that her work schedule had changed and she was unavailable in the evenings to complete the intervention. Thus, the parent opted to withdraw from the study.

The PR procedure was implemented in the participants' homes. Training was provided for the parents and students in a classroom at the school. Data were collected on reading performance at school by the investigator.

Dependent Measures. To assess the generalized effects of the PR procedure on reading performance at school, CBM probes were administered twice per week at school. During the 1-minute probes, the fluency (total number of words read) and accuracy (correct number of words read) were calculated. CBM probes were scored by the first author and audiotaped to facilitate assessment of interobserver agreement, which was conducted in a random fashion by a second independent observer following the conclusion of the study.

Ongoing measurement of students' reading skills is essential to document student progress objectively. CBM is an objective, ongoing measurement system. CBM requires testing to occur frequently over time using a standardized measurement system. Each test is an alternate form that encompasses the year-long curriculum (Fuchs, Fuchs, Hamlett, Walz, \& Germann, 1993).

A number of validation studies have consistently suggested that assessing reading fluency (oral reading rate) provides an overall picture of a child's reading decoding and comprehension (e.g., Deno, Mirkin, \& Chiang, 1982). Shapiro (1996) concluded that "correlations between measures of comprehension and oral reading rate are consistently higher than .70" (p. 112). Thus, Salvia and Hughes (1990) recommend that the number of words read correctly (accuracy) and oral reading rate (fluency) on passages be used to monitor student's reading progress. Generic probes (i.e., probes at 
the students' grade level, but not taken from the actual curriculum) to monitor students' progress provide a sensitive measure of change, regardless of the type (basal or whole language) or specific series in which instruction is occurring (Fuchs, 1989).

CBM probes from Standard reading passages (Child Educational Services) were used for progress monitoring for all students. The method used to find the appropriate level for progress monitoring was that described in the Standard reading passages manual. However, to alleviate the problem encountered by Law and Kratochwill (1993) in which many of the students in the study were reading at high levels on the progress monitoring probes, a "trial probe" at each student's suggested level was conducted. As a result of this probe, two of the three students were moved to the next difficulty level for progress monitoring. Standards for acceptable growth on CBM probes were identified as 1.0 words per week at Grade 3 and .85 words per week at Grade 4 (Fuchs et al., 1993).

To evaluate the students' progress on CBM measures, a similar method as that used by Hook and DuPaul (1999) was utilized. First, to fit a regression line within baseline and intervention phase data, slope values were generated using the Ordinary Least-Squares method (OLS). The OLS method was chosen because it has been found to be superior to other methods (Good \& Shinn, 1990). Next, the software program SPSS was used to calculate the slope of the OLS regression line. Effect sizes were calculated for the data using the following formula: ES = (median words read correctly during intervention-median words read correctly during baseline)/standard deviation of baseline data.

Woodcock-Johnson Tests of Achievement-Revised (Woodcock \& Johnson, 1989). The Woodcock-Johnson Psychoeducational Battery-R is an individually administered, standardized, and normreferenced achievement test. From the raw score earned by the child, a standard score and a grade equivalent can be calculated for each subtest. For the purpose of this study, two subtests were selected as a criterion for comparison against CBM data. The Letter-Word Identification subtest requires the student to read letters and words presented in a list format. The Passage Comprehension subtest requires the student to read a short passage from which a word has been omitted. The student must then state the word to complete the passage.

Training Parents in the PR Technique. Each parent/child dyad attended one training session of approximately 1 hour, which was conducted by the first author at the children's school. The first training session consisted of Bob and his mother, and Sue and her mother. The second training session consisted of Joe and his mother and father, and another student and her mother whom later dropped out of the study due to time constraints. Each training session followed an identical procedure. During each training session, the PR method was introduced, explained, and modeled by the first author and one of the children participating in the study. For example, the investigator first explained simultaneous reading. Then the first author and one of the children modeled simultaneous reading. Following this, each child and parent dyad practiced simultaneous reading while the investigator provided feedback. Next, the investigator explained the nonverbal signal to read independently and the independent reading phase of PR. Each child then selected his/her nonverbal signal. The investigator again modeled the use of the signal and independent reading with one of the children. Following this, the participants role-played using their signal and reading independently while the first author observed and provided corrective feedback.

During the next portion of the training session, the investigator provided a rationale for positive reinforcement during PR sessions. The investigator also provided parents with examples of ways to praise their child. The parents and children then used the PR method, with the parents providing praise to their children, while the investigator provided feedback. Finally, parents were instructed in timing and audiotaping of the PR. Also, each child was given a calendar on which to record PR sessions. 
Parent Tutoring Procedure. A PR method was utilized. Reading material was provided to each parent-student pair at the outset of the study. This material consisted of an older version of a basal reader that corresponded to each student's grade and instructional level. Parents were provided with a tape recorder and audiotapes to record each PR session for the purpose of evaluating treatment integrity.

Parents followed a structured protocol during the PR session (see Table 1 for outline). The session protocol was modeled after that used by Hook and DuPaul (1999) in their parent tutoring study. Each session included time to warm up. During this time the parent and child took a few minutes to discuss the events of the day. Next, the child selected the reading material for the session from the material provided.

PR began when the parent set a timer for 10 minutes. The parent and child began simultaneously reading the text, with the parent adjusting his/her rate to that of the child. If the child made an error (i.e., word substitution, omission, mispronunciation) or paused on one word for more than a parent count of three, the parent said the word correctly while pointing to it. The child then repeated the word and the pair continued in duet reading.

When the child desired to read independently, s/he gave the parent a predetermined nonverbal signal (e.g., knock on the table). The child was praised for giving the signal, and quiet approval (e.g., head nods) continued throughout independent reading. During this phase, if the child made an error (as defined above) or paused on a word for more than a parent count to three, the parent pointed to the word while saying it, and the child repeated the word. Duet reading then resumed until the child indicated a desire to read independently again.

After engaging in the PR method for 10 minutes, the parent and child spent a few minutes to cool down and talk about the story or about the PR session. A minimum of four sessions was conducted throughout each treatment week. Flexibility was granted to the parents and children regarding the time and days of these sessions.

Positive Reinforcement. Upon completion of four PR sessions in 1 week, the students were instructed to return the audiocassette to the first author. For returning the tape to the author, the child received a small reinforcer (i.e., pencil, eraser). Following completion of the study, each child was given a gift certificate to a local restaurant for participation.

Interrater and Interobserver Agreement. Interrater and interobserver agreement were calculated for CBM probes administered and scored by the first author and for the PR sessions scored by the first author. Following the completion of the study, an independent observer who was a graduate student in school psychology, served as the second rater. This graduate student was blind to the experimental procedure and phases of the study. She was trained in coding the CBM probes and in coding the PR sessions using forms constructed from Tables 1 and 2. During training, this observer received feedback and training until she was able to code with at least $85 \%$ accuracy on three trials for both CBM and PR.

Following the completion of the study, the tapes were randomized by participant and experimental phase. Percent agreement was calculated on a point-by-point basis, by dividing the number of agreements by the total agreements plus disagreements and multiplying by 100 . Mean percent agreement for CBM probes was $92 \%$. Mean percent agreement for PR sessions was $88 \%$.

\section{Experimental Design and Data Analysis}

A multiple probe design across participants was used to determine the effects of the PR method on reading performance. This resulted in the baseline, intervention, first follow-up, and second 
Table 2

Slope Values and Mean Words Correct Per Minute Across Experimental Phases and Corresponding Effect Sizes

\begin{tabular}{lccc}
\hline Slope Values & Baseline & Paired Reading & Effect Size \\
\hline Bob & -.477 & .593 & 2.038 \\
Sue & 1.16 & .469 & .968 \\
Joe & .813 & -.169 & .652 \\
Mean Words Correct Per Minute & Baseline & Paired Reading & Follow Up \\
\hline Bob & $80.7(171)^{\mathrm{a}}$ & $93.3(184)$ & $112(219)$ \\
Sue & $64.3(107)$ & $66.4(110)$ & $77(113)$ \\
Joe & $67(107)$ & $73.4(110)$ & $89.5(113)$ \\
\hline
\end{tabular}
peers.

${ }^{a}$ Values in parentheses represent mean words correct per minute for comparison

follow-up phases for the first student (Bob) to be 7, 30, 55, and 65 days, respectively. For the second student (Sue), the phases were 12, 25, 55, 65 days, respectively. The final student's (Joe) phases were $19,18,55$, and 65 days, respectively. The administration of CBM probes at school began in the baseline phase, continued during the PR phase, and was discontinued until the 4-week and 6-week follow-up phase. At the 4-week follow-up, each of the three students was administered a 1-minute CBM probe by the first author. At the 6-week follow-up, each of the three students and the two peer comparison students were administered a 1-minute CBM probe. The follow-up probes were administered using procedures identical to those used throughout the study.

\section{Results}

\section{Reading Performance}

The results of the CBM probes administered twice per week by the investigator are presented in Figure 1. Table 2 summarizes mean words correct per minute (wcpm) on CBM probes, slope values, and effect sizes. Positive effect sizes were found for all participants, ranging from .652 to 2.038. In addition, for all three students, words correct per minute at follow-up were higher than their original baseline levels.

The split-middle method (Tawney \& Gast, 1984) was used to verify the visual analysis. During the baseline phase, Bob and Sue's data showed a slightly ascending trend, while Joe's trend line appeared flat. All three students displayed variability in the baseline data. During the intervention phase, the trend lines for Bob and Sue were improving, whereas for Joe, the trend was descending. All three students displayed variability in the data during the intervention phase. However, Bob's data became less variable toward the end of the intervention phase.

Select subtests of the Woodcock-Johnson Tests of Achievement-Revised were administered prior to and following the PR intervention as an additional measure of students' progress. The results of the achievement testing are listed in Table 3. All students made substantial gains on this measure.

\section{Treatment Integrity}

For the first six sessions, mean treatment integrity ratings were $97 \%$ for Bob, $95 \%$ for Sue, and $97 \%$ for Joe. For all of the pairs, treatment integrity remained above $85 \%$ throughout the course of the study. 


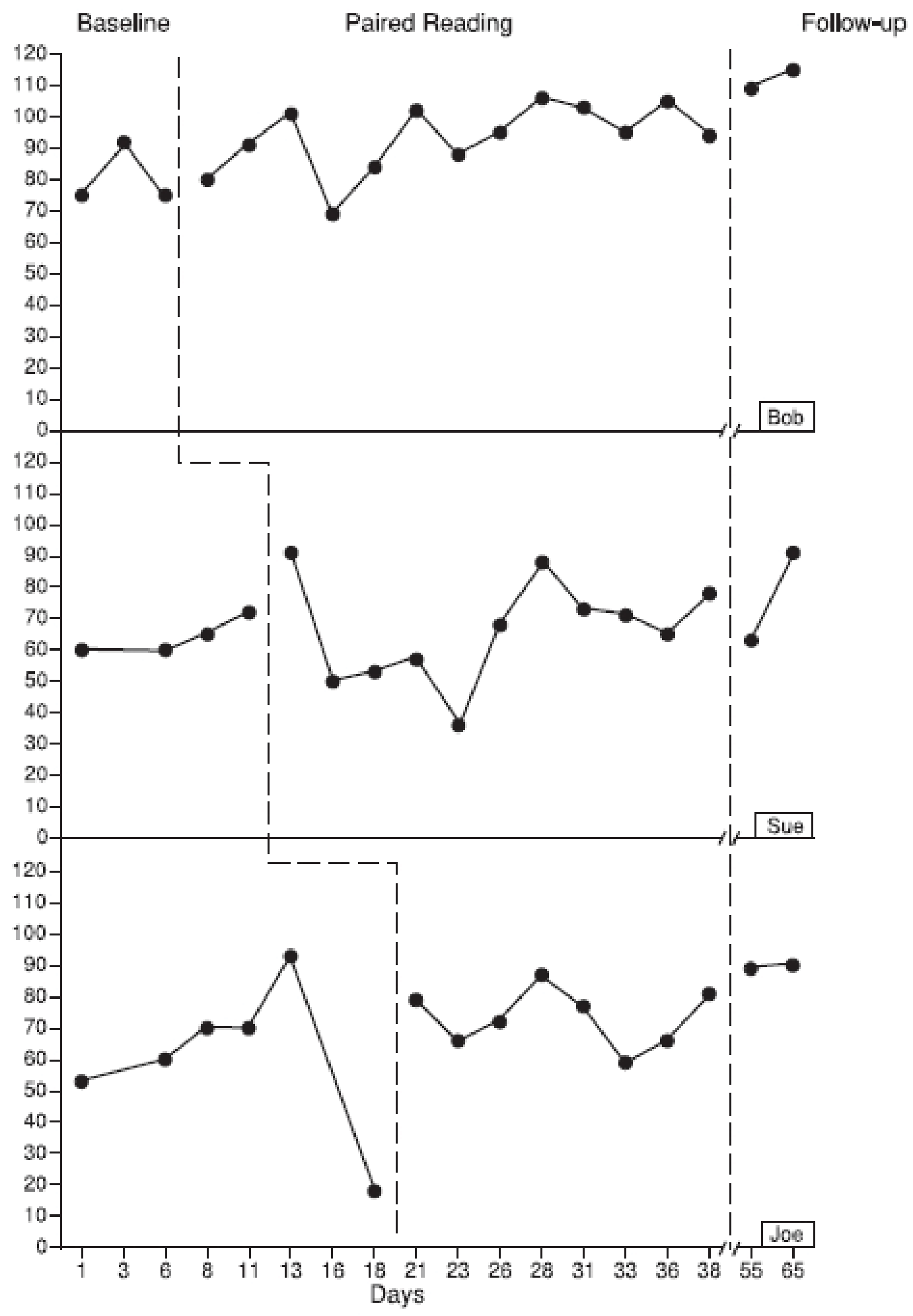

Figure 1 . Words read correctly per minute by participants across experimental phases. 
Table 3

Pre- and Posttesting Scores on Woodcock-Johnson Subtests

\begin{tabular}{lcclcc}
\hline & \multicolumn{2}{c}{ Letter-Word Identification } & & \multicolumn{2}{c}{ Passage Comprehension } \\
\cline { 2 - 3 } \cline { 5 - 6 } & Pre & Post & & Pre & Post \\
\hline Bob & 3.8 & 4.7 & & 3.0 & 3.9 \\
Sue & 3.1 & 4.1 & & 3.9 & 5.1 \\
Joe & 3.1 & 4.4 & & 3.0 & 4.2 \\
\hline
\end{tabular}

Note: Scores presented are grade equivalents

\section{Social Validity}

Social Comparison. Peer comparison data were collected to compare target students' progress with that of average readers at their respective grade levels. Table 2 includes the mean words correct per minute for comparison peers. None of the participants' data overlapped those of the comparison peers, although they became closer. When comparing fluency at baseline to follow-up, students participating in the study made mean gains comparative to that of the peer comparisons.

Treatment Acceptability. At the conclusion of the intervention phase, the students were asked to complete a modified Children's Intervention Rating Profile. Students' comments about PR were mostly positive. The modified CIRP consisted of six questions, which were rated on a Likert scale of 1 to 5 , with 5 being the highest. The maximum possible score on the scale was 22. Mean ratings for each student was 4 .

Parent acceptability of the PR procedure was assessed with a revised Intervention Rating Profile. The Intervention Rating Profile was revised, and consisted of 12 items rated on a six-point Likert scale, with a rating of 6 being the highest (Strongly Agree). Table 4 lists the items and the mean rating for each. Overall, ratings and anecdotal comments by parent participants were primarily positive. Mean item ratings revealed means of 5.91, 5.5, and 5.67 for the parent responses of Bob, Sue, and Joe, respectively. The parents rated all statements as either Agree or Strongly Agree.

Table 4

\section{Modified Intervention Rating Profile with Mean Ratings}

1. The child's reading problem is severe enough to warrant use of this intervention. (5.33)

2. This intervention should prove effective in changing the child's reading problem. (5.67)

3. This would be an acceptable intervention for the child's reading problem. (5.67)

4. Overall, the intervention would be beneficial for the child. (6.0)

5. This intervention would be appropriate for use before making a referral. (5.67)

6. This intervention would not result in negative side effects for the child. (6.0)

7. This intervention would not result in risk to the child. (6.0)

8. This intervention would not be considered a "last resort." (6.0)

9. This intervention is practical in the amount of time required for the parent contact. (5.33)

10. This intervention is practical in the amount of time required for contact with supervising staff. (6.0)

11. This intervention is practical in the amount of time required for record keeping. (5.33)

12. This intervention is practical in the amount of out-of-school time required for implementation. (5.33) 


\section{Discussion}

Past researchers have suggested that parent tutoring results in an increase in reading achievement (e.g. Fitton \& Gredler, 1996; Hook \& DuPaul, 1999), and PR has been the focus of numerous studies. In general, these studies have shown support for PR; however, some have produced conflicting results. In addition, past research has not been of the highest scientific quality. Specifically, few studies monitored if parents implemented the procedure with integrity; most studies measured progress solely through pre-and poststandardized measures (which may not be a sensitive measure of true reading progress); and past research failed to monitor the reading material from which the parent and child read. The current study addressed these limitations by (a) monitoring the integrity with which parents implemented the PR procedure; (b) used CBM as the primary outcome measure; and (c) attended to the specific reading materials from which the parent and child read (Law \& Kratochwill, 1993).

The main purpose of this study was to examine the effectiveness of parents tutoring their children in reading via the PR method. Based upon visual analysis of data, results of the current study revealed improvements in reading performance for two of the students (Bob and Sue). Slope data provided supporting evidence that increases in reading performance were present for two students during the intervention phase. One difference among the participant data was found in examining Bob's data. Bob's data appear to have stabilized in the latter portion of the intervention phase, which was also the case at the end of Sue's intervention phase. Joe, who had the shortest intervention phase, displayed variability throughout intervention. This pattern, when considered with the length of each students' intervention phase, suggests that a longer intervention period may produce more stable data (Law \& Kratochwill, 1993). The majority of PR studies have asked parents to use the procedure for 10 minutes per session, 5 days per week, for 6 weeks (Law \& Kratochwill, 1993; Lindsay, Evans, \& Jones, 1985; Topping \& Whiteley, 1990). In the current study, parents were asked to use PR for 10 minutes per session, 4 days per week. The intervention phase for the students in this study varied across the three students (6 weeks, 5 weeks, and 3.5 weeks). Comparing methods of estimating slope, Good and Shinn (1990) found a substantial increase in accuracy was demonstrated when using 20 data points rather than 10. In the present study, the number of data points ranged from 8 to 13 during the intervention phase. Therefore, increasing the length of the study and the number of data points may have provided more interpretable data.

Many other studies involving PR have reported outcomes with either CBM data or pre/ posttest data, with most using the latter method (Miller \& Kratochwill, 1996; Topping \& Whiteley, 1993). In the current study, both methods were utilized to measure progress. In examining these two methods for Bob and Sue, it appears that CBM and the pre/posttesting yielded similar results to those achieved during the intervention phase: a positive reading gain. However, Joe's CBM and pre/postdata yielded conflicting results. According to the CBM data during the intervention phase, Joe's performance resulted in a descending trend line. The pre/postachievement test data revealed that Joe's skills in decoding words (Letter-Word Identification) increased 1.3 grade levels, and his ability to understand what he was reading (Comprehension) increased 1.2 grade levels. This was a greater gain than was reported for the other two students. This discrepancy demonstrates the concerns with using pre/posttest data as the sole method of measuring student performance.

Another way to analyze the data is to examine the words gained per week in comparison to the expected gains outlined by Fuchs et al. (1993). Realistic expectations, with basic classroom reading instruction, would be a gain of 1.0 words per week at grade 3 , and .85 words per week at grade 4 . Table 2 shows the mean words the students in this study read from baseline to follow-up. Sue went from reading 64.3 words correct per minute (wcpm) at baseline to reading $77.0 \mathrm{wcpm}$ at follow-up. This gain of 12.7 wcpm was made over the 13 weeks of the study. Thus, Sue, a third grader, gained 
approximately .98 wcpm per week. The other third grade student, Joe, gained 1.73 wcpm per week. Both students met or exceeded the expected gains as outlined by Fuchs et al. (1993). The fourthgrade student, Bob, gained approximately 2.4 wcpm per week. Bob's gain more than doubled the expectation. Based on this information, it appears that all students met or exceeded the expectations of words gained per week during the PR intervention when specifically using CBM guidelines.

The parents in the current study implemented the PR technique with integrity following minimal training. In Law and Kratochwill's (1993) study, a high degree of variability in treatment integrity was noted, with one parent receiving an average performance rating of $98.6 \%$ and another obtaining a mean performance rating of only $63.8 \%$. In the present study, treatment integrity averaged between 89 and $97 \%$ throughout the course of the study. The difference in these results may be explained by examining the training the parents received in previous research. Law and Kratochwill trained 16 parents in one large group, wherein parents watched a video and practiced PR with another adult. In the present study, a smaller group format was utilized, and the children were included. Specifically, the first training group consisted of two parents, two children, and the trainer. The second training group consisted of three parents, two children, and the trainer. Parents and children established their nonverbal signal and practiced the PR method. The trainer observed and provided immediate feedback. This allowed for those parents who needed additional support and practice to receive it immediately.

Although one parent-child pair had some difficulty implementing the PR method due to time or family constraints, consumer satisfaction ratings of this intervention were rated in a positive light by parents and children. Parents indicated high ratings overall. Slight concerns reported anecdotally and on the questionnaires were related to the amount of time required for implementing the intervention. Children also rated the intervention quite positively. One question, asking the students to rate if there would have been better ways to improve his/her reading skills, received a lower rating than the other questions.

Finally, one element of the PR technique is that the child is given control over the reading material for the PR sessions. This is viewed as a positive aspect of PR in that the child may be more interested in reading material that is self-selected (Fitton \& Gredler, 1996). However, this may lead to frustration in reading if the child chooses material that is too difficult for his/her ability level (Miller \& Kratochwill, 1996).Also, Duvall et al. (1992) found that providing material for home tutoring similar to that used for instruction at school generalized to increased proficiency in school material. Fitton and Gredler (1996) proposed that although children may initially make mistakes in choosing material that is either too easy or too difficult, they will eventually find the appropriate level. This has not been investigated in PR research. The current study offers an appropriate compromise because the level of the reading material was controlled, while children were allowed the power to choose the specific reading material for each session.

\section{Limitations}

Several limitations are noteworthy in examining the results of the present study. One limitation was the variability of the data, which made it difficult to discern if true gains were made by the students. This variability was most likely due to the length of the intervention phases for Sue and Joe. It appeared that the longer intervention used for Bob may have produced more pronounced, stable CBM results. A minimum of 6 to 7 weeks, with 20 or more CBM data points, may be needed for the intervention phase in PR studies.

Although treatment integrity for all participants appeared high, one student (Sue) anecdotally reported to the first author that on some nights she and her mother completed two PR sessions in one evening to help them "catch up." In listening to the tapes, these sessions were recorded as two 
separate sessions occurring on 2 separate days. Thus, it is difficult to discern if this pair truly implemented the procedure as prescribed. Although general treatment integrity was assessed, certain aspects of the intervention were not captured (e.g., scheduling of sessions). This may indicate the need to broaden the intervention and increase the number of individuals capable of and responsible for its implementation. For example, if the child has two adults in his/her home, it may be beneficial to train both adults in the PR method. Then, if one adult was unavailable to take part in the PR session, the other adult could serve as the child's partner. Another option is to allow one adult in the home to train another adult. Hook and DuPaul (1999) noted similar difficulty with parents' time constraints. In their study, parents implemented the tutoring procedure only two to three times per week rather than the agreed upon three to four times per week.

\section{Directions for Future Research}

The present study yielded some promising results, and also raised issues in need of investigation. Future research may explore whether or not a longer intervention phase produces more pronounced and stable results. In addition, it may be interesting to measure the effects when students have access to their CBM data. Throughout the current study, the students often asked how many words they read or how they did on the CBM probe. They were given a generic response such as "You did a great job." By having students chart their results, the students may have incentive to give their best effort for each reading.

Another direction for future research is the investigation of the effectiveness of parents training other parents in the PR method. This may provide extra support and allow parents to demonstrate increased treatment integrity. It may also alleviate the problem of parents not participating in the study or dropping out due to time constraints.

\section{REFERENCES}

Adams, M.J. (1990). Beginning to read: Thinking and learning about print. Cambridge, MA: The MIT Press.

Deno, S.L., Mirkin, P.K., \& Chiang, B. (1982). Identifying valid measures of reading. Exceptional Children, 49, $36-47$.

Duvall, S.F., Delquadri, J.C., Elliott, M., \& Vance Hall, R. (1992). Parent-tutoring procedures: Experimental analysis and validation of generalization in oral reading across passages, settings, and time. Journal of Behavioral Education, 2, 281-303.

Elliott, J.A., \& Hewison, J. (1994). Comprehension and interest in home reading. British Journal of Educational Psychology, 64, 203-220.

Fitton, L., \& Gredler, G. (1996). Parental involvement in reading remediation with young children. Psychology in the Schools, 33, 325-332.

Fredericks, A.D., \& Rasinski, T.V. (1990). Working with parents: Involving the uninvolved: How to. The Reading Teacher, 43, 424-425.

Fuchs, L.S. (1989). Evaluating solutions: Monitoring progress and revising intervention plans. In M.R. Shinn (Ed.), Curriculum-based measurement: Assessing special children (pp. 153-181). New York: Guilford.

Fuchs, L.S., Fuchs, D., Hamlett, C.L., Walz, L., \& Germann, G. (1993). Formative evaluation of academic progress: How much growth can we expect? School Psychology Review, 22, $27-48$.

Good, R.H., \& Shinn, M.R. (1990) Forecasting accuracy of slope estimates for reading curriculum-based measurement: Empirical evidence. Behavioral Assessment, 12, 179-193.

Good, R.H., Simmons, D.C., \& Smith, S.B. (1998). Effective academic intervention in the United States: Evaluating and enhancing the acquisition of early reading skills. School Psychology Review, 27, 45-56. 
Graue, M.E., Weinstein, T., \& Walbert, H.J. (1983). School-based home instruction and learning: A quantitative synthesis. Journal of Educational Research, 76, 351-360.

Hook, C.L., \& DuPaul, G.J. (1999). Parent tutoring for students with attention-deficit/hyperactivity disorder: Effects on reading performance at home and school. School Psychology Review, 28, 60-75.

Law, M., \& Kratochwill, T.R. (1993). Paired reading: An evaluation of a parent tutorial program. School Psychology International, 14, 119-147.

Leach, D.J., \& Siddall, S.W. (1990). Parental involvement in the teaching of reading: A comparison of hearing reading, paired reading, pause, prompt, praise, and direct instruction methods. British Journal of Educational Psychology, 60, 349-355.

Lindsay, G., Evans, A., \& Jones, B. (1985). Paired reading versus relaxed reading: A comparison. British Journal of Educational Psychology, 55, 304-309.

McMackin, M. (1993). The parent's role in literacy development. Childhood Education, 69, 142-145.

Martens, B.K., Witt, J.C., Elliott, S.N., \& Darveaux, D. (1985). Teacher judgements concerning the acceptability of school-based interventions. Professional Psychology: Research and Practice, 16, 191-198.

Miller, B.V., \& Kratochwill, T.R. (1996). An evaluation of the paired reading program using competency-based training. School Psychology International, 17, 269-291.

Morrow, L.M., \& Young, J. (1997). A family literacy program connecting school and home: Effects on attitude, motivation, and literacy achievement. Journal of Educational Psychology, 89, 736-742.

Salvia, J., \& Hughes, C. (1990). Curriculum-based assessment: Testing what is taught. New York: Macmillan.

Sattler, J.M. (1992). Assessment of children: WISC-III and WPPSI-R supplement. San Diego: Author.

Shapiro, E.S. (1996). Academic skills problems: Direct assessment and intervention (2nd ed.). New York: The Guilford Press.

Stanovich, K.E. (1986). Matthew effects in reading: Some consequences of individual differences in the development of reading fluency. Reading Research Quarterly, 21, 360- 406.

Tawney, J.W. \& Gast, D.L. (1984). Single subject research in special education. Columbus, OH: Merrill.

Tizard, J., Schofield, W.N., \& Hewison, J. (1982). Collaboration between teachers and parents in assisting children's reading. British Journal of Educational Psychology, 52, 1-5.

Toomey, D. (1993). Parents hearing their children read: A review. Rethinking the lessons of the Haringey Project. Educational Research, 35, 223-236.

Topping, K.J., \& Lindsay, G.A. (1992). The structure and development of the Paired Reading approach. Journal of Reading Research, 15, 120-136.

Topping, K., \& Whiteley, M. (1990). Participant evaluation of parent-tutored and peer-tutored projects in reading. Educational Research, 32, 14-27.

Wagner, R.K., Torgesen, J.K., Rashotte, C.A., Hecht, S.A., Barker, T.A., Burgess, S.R., Donahue, J., \& Garon, T. (1997). Changing relations between phonological processing abilities and word-level reading as children develop from beginning to skilled readers: A 5-year longitudinal study. Developmental Psychology, 33, 468- 479 .

Wechsler, D. (1991). Wechsler Intelligence Scale for Children (3rd ed.). New York: Psychological Corporation.

Weinberger, J. (1996). A longitudinal study of children's early literacy experiences at home and later literacy development at home and school. Journal of Research in Reading, 19, 14-24.

Witt, J.C., \& Elliott, S.N. (1985). Acceptability of classroom intervention strategies. In T.R. Kratochwill (Ed.), Advances in school psychology (vol. IV, pp. 251-288). Hillsdale, NJ: Erlbaum.

Witt, J.C., \& Martens, B.K. (1983). Assessing the acceptability of behavioral interventions used in classrooms. Psychology in the Schools, 20, 510-517.

Woodcock, R.W., \& Johnson, M.B. (1989). Woodcock-Johnson Psychoeducational Battery-Revised. Allen, TX: DLM. 